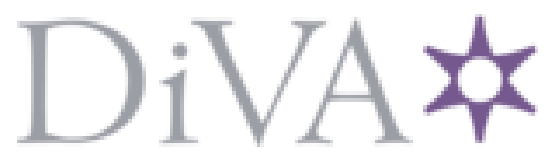

http://www.diva-portal.org

This is the published version of a paper published in Journal of Computational Methods in Sciences and Engineering.

Citation for the original published paper (version of record):

Tunå, P., Svensson, H., Brandin, J. (2015)

Modelling of a reverse-flow partial oxidation reactor for synthesis gas production from gasifier product gas..

Journal of Computational Methods in Sciences and Engineering, 15(3): 593-604

http://dx.doi.org/10.3233/JCM-150545

Access to the published version may require subscription.

N.B. When citing this work, cite the original published paper.

Permanent link to this version:

http://urn.kb.se/resolve?urn=urn:nbn:se:Inu:diva-46182 


\title{
Modelling of a reverse-flow partial oxidation reactor for synthesis gas production from gasifier product gas
}

\author{
Per Tunåa $^{\mathrm{a}}$, Helena Svensson ${ }^{\mathrm{a}}$ and Jan Brandin ${ }^{\mathrm{b}, *}$ \\ ${ }^{a}$ Department of Chemical Engineering, Lund University, Lund, Sweden \\ ${ }^{\mathrm{b}}$ Build Environment and Energy Technology, Linnaeus University, Växjö, Sweden
}

\begin{abstract}
Biomass gasification followed by fuel synthesis is one of the alternatives for producing liquid fuels and chemicals from biomass feedstocks. The gas produced by gasification contains $\mathrm{CO}, \mathrm{H}_{2}, \mathrm{H}_{2} \mathrm{O}, \mathrm{CO}_{2}$, light hydrocarbons and tars. The light hydrocarbons can account for as much as $50 \%$ of the total energy content of the gas, depending on the type of gasifier, operating conditions and feedstock. The gas also contains catalyst poisons such as sulphur, in the form of $\mathrm{H}_{2} \mathrm{~S}$ and COS. This paper presents simulations of a reverse-flow partial-oxidation reformer that converts the light hydrocarbons into more synthesis gas, while achieving efficiencies approaching that of conventional catalytic processes. Variations in parameters such as pressure, amount of oxidant and steam-to-carbon ratio were also investigated. Simulations of the reforming of natural gas were included for comparison. The results show the benefits of using reverse-flow operation with lean gases such as gasifier product gas.
\end{abstract}

Keywords: Mathematical modelling, gases, chemical reactors, packed bed, simulation, dynamic simulation

\section{Introduction}

The production of liquid fuels from renewable resources is one way of reducing our dependency on fossil fuels. One of the methods that can be used is the gasification of biomass such as energy crops, agricultural waste and forest residues. The gas produced can then be processed to provide synthesis gas that can be used for the production of liquid fuels such as methanol or Fischer-Tropsch diesel.

The composition of the gas produced by gasification is highly dependent on the type of gasifier, the operating conditions and the feedstock used. The major components of the gas are $\mathrm{CO}, \mathrm{CO}_{2}, \mathrm{H}_{2}, \mathrm{H}_{2} \mathrm{O}$ and $\mathrm{N}_{2}$, when air is used for gasification. The gas may also contain non-negligible amounts of lower hydrocarbons $\left(\mathrm{C}_{1}-\mathrm{C}_{3}\right)$ and tars, as well as traces of $\mathrm{H}_{2} \mathrm{~S}, \mathrm{COS}, \mathrm{NH}_{3}$ and $\mathrm{HCN}$. If synthesis gas is to be produced, the hydrocarbons present in the gas must be converted to $\mathrm{CO}$ and $\mathrm{H}_{2}$. Catalytic techniques are not suitable for this conversion due to the contaminants present in the gas, mainly sulphur. Conventional catalysts used for reforming purposes are usually nickel-based and are highly susceptible to sulphur poisoning [1-3]. A non-catalytic technique, for instance, partial oxidation, for converting the hydrocarbons is therefore an interesting alternative. The major drawback of using non-catalytic partial oxidation

\footnotetext{
${ }^{*}$ Corresponding author: Jan Brandin, Build Environment and Energy Technology, Linnaeus University, SE-351 95 Växjö, Sweden. Tel.: +46 765 920781; E-mail: Jan.Brandin@LNU.se.
} 
(POX) is that higher temperatures are required than in auto-thermal reforming (ATR) or steam reforming (SREF), making the process more energy demanding. In order to avoid this problem, a reverse-flow reactor system has been suggested. This concept was first reported for the combustion of low calorific gases, and has been extensively studied over the years [4-17]. Several industrial applications of the technique exist, mainly as regenerative thermal oxidation, for the removal of volatile organic compounds and regenerative catalytic oxidation.

A reverse-flow system consists of a reactor filled with a granular material with high thermal capacity which acts as a heat buffer. Two heat buffers are placed on either side of a reaction zone that requires a high temperature. If a cold gas is flowed into the first (hot) heat buffer, the gas heats up and at the same time, the buffer is cooled down. The gas then enters the reaction zone where heat is released from the gas to the packed bed due to partial oxidation of the gas. The hot gas flows from the reaction zone through the second (cold) heat buffer and heats the buffer and cools the gas. Heat is effectively transferred from the first to the second heat buffer. When the flow is reversed, the heat is moved back to the first heat buffer and the cycle is completed. The flow direction is reversed periodically, when the outlet reaches a specified temperature, the switching temperature, during operation. Eventually, a pseudo-steady-state temperature profile is established, with a high temperature in the middle of the reactor and a lower temperature at the inlet and outlet.

This paper presents a mathematical model of a reverse-flow process for reforming a gasifier product gas to produce synthesis gas. To the best of our knowledge, this is the first paper presented on partial oxidation of a gasifier product gas using the reverse-flow concept. Previous work in this field has been focused on partial oxidation of pure methane or natural gas [18-22]. The reforming of a gasifier product gas presents unique challenges as the gas contains not only methane but also hydrogen and other hydrocarbons. Simulations were performed to identify the best reactor design and the effects of varying the operating parameters for future experimental studies.

\section{The mathematical model}

The reverse-flow reformer is a plug flow reactor with an inert packing material. The packing consists of spherical particles and its role is to act as a heat buffer. The packing material used during simulations is sintered $\alpha$-alumina. In order to model a dynamic system such as the reverse-flow reformer, it is important to accurately model the kinetics of the reactions taking place. It is also important to describe the system in sufficient, but not excess, detail. Making the model more detailed than necessary will result in a high degree of complexity, making the simulations very time-consuming, thus counteracting the purpose of modelling.

The reverse-flow reformer is described by a model designed to accurately simulate the dynamic behaviour of the reactor. The gas phase is modelled as a series of tank reactors, in this case 31 . This simplifies the mass balances and the energy balance for the gas phase, making the calculations less demanding. The composition of the outgoing stream from each tank is used as the composition of the ingoing stream in the following tank in the series. In order to solve the system for the solid phase, the partial differential equation expressing the energy balance must be discretized in space. The second-order derivative is approximated by a centred-difference approximation.

The simulations were performed using a $\mathrm{C}++$ program due to its advantages over scripted programs. A pre-compiled program can be optimized upon compilation allowing the use of several CPU floatingpoint and vector math operation enhancements, whereas a script requires an interpreter, and is therefore limited by the speed of interpretation. This becomes clearer in programs that perform several million 
mathematical operations. A third-party library, Cantera, was used to calculate thermodynamics and kinetics. The differential equation solver used was DASPK3.0 [27].

\subsection{Kinetics and thermodynamics}

Cantera is a free library using $\mathrm{C}++$ which also supports MATLAB and Python. Cantera uses the GRI-Mech 3.0 mechanism to describe the kinetics [23]. This mechanism consists of 53 species and 325 reactions, and was originally designed to model the combustion of natural gas. The GRI-Mech 3.0 mechanism was optimized for the following conditions: temperature $1000-2500 \mathrm{~K}$, pressure $1.3-$ $1000 \mathrm{kPa}$ and an equivalence ratio (the ratio of fuel to oxidiser) of $0.1-5$ for premixed systems. This mechanism has been shown to give results that agree well with experimental data obtained from reforming processes [24].

\subsection{Mass balances}

The mathematical model describing the plug flow reactor consists of one mass balance Eq. (1) for each component. A dispersion term and a convection term are included in the mass balance for each component, as well as the contribution from the reactions.

$$
\varepsilon \rho_{g} \frac{\partial y_{i}}{\partial t}=\varepsilon \frac{L}{P e_{m}} n_{g} \frac{\partial^{2} y_{i}}{\partial z^{2}}-n_{g} \frac{\partial y_{i}}{\partial z}+\varepsilon \Sigma_{j} \nu_{i j} r_{j}
$$

See the notation for an explanation of the variables and constants used.

As the gas phase was modelled as a series of tank reactors this expression is further simplified, see Eqs (2) and (3). Cantera's general reaction model solves one mass conservation balance for the reactor, and one species conservation balance for each component included in the reaction mechanism. The total mass in the reactor changes due to the flow through the inlet and outlet and as a result of the homogeneous reactions that take place in the reactor, as described in Eq. (2).

$$
\frac{d m}{d t}=\Sigma_{\text {in }} \dot{m}_{\text {in }}-\Sigma_{\text {out }} \dot{m}_{\text {out }}+\dot{m}_{\text {prod }}
$$

where $m$ is the mass of the components in the reactor.

The rate of change of each component, $k$, is described by Eq. (3).

$$
\frac{d m x_{k}}{d t}=\Sigma_{\text {in }} \dot{m}_{\text {in }} Y_{k, \text { in }}-\Sigma_{\text {out }} \dot{m}_{\text {out }} x_{k, \text { out }}+\dot{m}_{k, \text { prod }}
$$

where $x_{k}$ is the mass fraction of each species.

\subsection{Energy balances}

The energy balance for the solid material consists of a conduction term and a heat transfer term. In the general model describing the energy balance for a plug flow reactor, a term for heat transfer is also included in the energy balance of the gas phase, since heat transfer occurs between the solid and the gas phase. Only convective transport is included in the gas phase since this dominates due to the high gas flow rate through the reactor, and the contribution from conduction can thus be considered negligible. The energy balance for the gas phase also contains the heat of reaction for all reactions taking place since the system is considered non-catalytic and all reactions are assumed to take place in the gas phase. 
Solid:

$$
\rho_{b} c_{k} \frac{\partial T_{s}}{\partial t}=\lambda_{e} \frac{\partial^{2} T_{s}}{\partial z^{2}}+\alpha S\left(T_{g}-T_{s}\right)
$$

Gas:

$$
\varepsilon \rho_{g} c_{p, g} \frac{\partial T_{g}}{\partial t}=-n_{g} c_{p, g} \frac{\partial T_{g}}{\partial z}+\alpha S\left(T_{s}-T_{g}\right)-\Sigma \Delta H_{i} r_{i}
$$

For the solid phase, a second order derivative is included for the heat conduction.

As the gas phase was modelled as a series of tank reactors Eq. (5) is further simplified. The energy conservation balance for the gas phase, solved by Cantera for each reactor in the reactor network, is described by Eq. (6).

$$
\frac{d U}{d t}=-P \frac{d V}{d t}-\alpha S\left(T_{g}-T_{s}\right)+\Sigma_{i n} \dot{m}_{\text {in }} h_{\text {in }}-h \Sigma_{\text {out }} \dot{m}_{\text {out }}
$$

where $U$ is the total internal energy of the reactor, $P$ is the pressure in the reactor, $V$ is the volume of the reactor, $\alpha S\left(T_{g}-T_{s}\right)$ is the heat transfer term and $h$ is the enthalpy.

\subsection{Initial conditions and boundary conditions}

The initial conditions and the boundary conditions for the mathematical model describing the plug flow reactor are given below.

When the simulation starts, the gas and the solid have the same temperature over the length of the reactor, described by the function $f(z)$ :

$$
t=0 \quad T_{s}(z, 0)=T_{g}(z, 0)=f(z)
$$

At the inlet, the gas has the same temperature as the incoming gas:

$$
z=0 \quad T_{g}=T_{g, i n}
$$

At the inlet, the solid temperature derivate is given by the difference between the solid temperature and the incoming gas temperature:

$$
\left.\frac{\partial T_{s}}{\partial z}\right|_{z=0}=\frac{1-\varepsilon}{\lambda_{s}} \alpha\left(T_{s}(0, t)-T_{g, i n}\right)
$$

The concentration derivate, for each component, at the inlet is given as the difference between the actual concentration and the concentration in the incoming flow:

$$
\left.\varepsilon D_{\text {eff }} \frac{1}{u} \frac{\partial y_{i}}{\partial z}\right|_{z=0}=y_{i}(0, t)-y_{i, i n}
$$

At the exit the temperature derivate is set to zero:

$$
z=\left.L \quad \frac{\partial T_{s}}{\partial z}\right|_{z=L}=0
$$

At the exit the concentration derivate is set to zero:

$$
\left.\frac{\partial y_{i}}{\partial z}\right|_{z=L}=0
$$

As the gas phase was modelled as a series of tank reactors the boundary conditions described above for the gas phase were not used as Cantera solves the mass and energy balances. 
Table 1

Compositions (\%) of the gases used in the simulations. The gasifier product gas composition is typical for that produced with a pressurised circulating fluidised bed [26]. The natural gas composition was that given by a gas supplier

\begin{tabular}{ccc}
\hline Component & Gasifier product gas & Natural gas \\
\hline $\mathrm{N}_{2}$ & - & 0.5 \\
$\mathrm{CO}_{2}$ & 27.8 & 0.5 \\
$\mathrm{C}_{2} \mathrm{H}_{6}$ & - & 4.5 \\
$\mathrm{C}_{3} \mathrm{H}_{8}$ & - & 2.5 \\
$\mathrm{CH}_{4}$ & 8.1 & 92.0 \\
$\mathrm{CO}$ & 11.8 & - \\
$\mathrm{H}_{2} \mathrm{O}$ & 37.6 & - \\
$\mathrm{C}_{2} \mathrm{H}_{4}$ & 3.0 & - \\
$\mathrm{H}_{2}$ & 11.7 & - \\
\hline
\end{tabular}

Table 2

Properties for the reactor used for simulations

\begin{tabular}{ll}
\hline Property & Value \\
\hline Length & $1.0 \mathrm{~m}$ \\
Diameter & $0.1 \mathrm{~m}$ \\
Inlet gas flow & $6 \mathrm{Ndm}^{3} / \mathrm{min}$ \\
Inlet temperature & $873 \mathrm{~K}$ \\
Switching temperature & $1000 \mathrm{~K}$ \\
Bed particle size & $1 \mathrm{~mm} \mathrm{spheres}$ \\
\hline
\end{tabular}

\subsection{Evaluation criteria}

Two different gas compositions were tested to evaluate the capabilities of the regenerative reformer, a typical producer gas from gasified biomass, and for comparison, natural gas. The compositions of the gasifier product gas and the natural gas are given in Table 1.

The reformer efficiency was defined based on the lower heating value (LHV) as:

$$
\eta=\frac{L H V_{C O+H_{2} \text { out }}}{L H V_{\text {total in }}}
$$

$\mathrm{LHV}_{\mathrm{CO}+\mathrm{H}_{2} \text { out }}$ is the combined LHV of $\mathrm{CO}$ and $\mathrm{H} 2$, which are the desired end products. $\mathrm{LHV}_{\text {total in }}$ is the combined LHV for all components in the inlet gas stream.

In the case of natural gas, the enthalpy of the additional steam was added to $\mathrm{LHV}_{\text {total in }}$. Both the methane conversion and the efficiency in the reactor must be considered when determining the effects of the different parameters. If the steam-to-carbon ratio in the gas is too low, the equilibrium becomes unfavourable and the potential methane conversion is too low, but at the same time requires less heat for steam generation. High steam-to-carbon ratios, on the other hand, reduce the soot formation and the equilibrium favours a higher methane conversion. Industrial POX reactors usually produce some soot, although this can be controlled somewhat by steam injection [25]. Since a POX reactor is simply an empty tube, any soot that forms is removed from the gas after the reactor when the gas is quenched with water to bring down the temperature. However, in the case of reactors containing catalysts or other packing material, soot formation can cause clogging, leading to considerable pressure drops over the reactor. Since the efficiency calculations include the energy in the steam, and because additional steam is needed to reform natural gas, the efficiency for natural gas is generally lower. It is therefore difficult to compare the efficiency of a methane-rich gas such as natural gas, with that for a lean gas such as gasifier producer gas.

\section{Results}

Most reverse-flow reactors have the oxygen inlet in the middle of the reactor. This has the advantage of only requiring one inlet, but only half of the reactor volume can be utilized. It was decided to insert pipes into the reactor such that oxygen could be added to either end of the wider section of the reactor (see Fig. 1). 


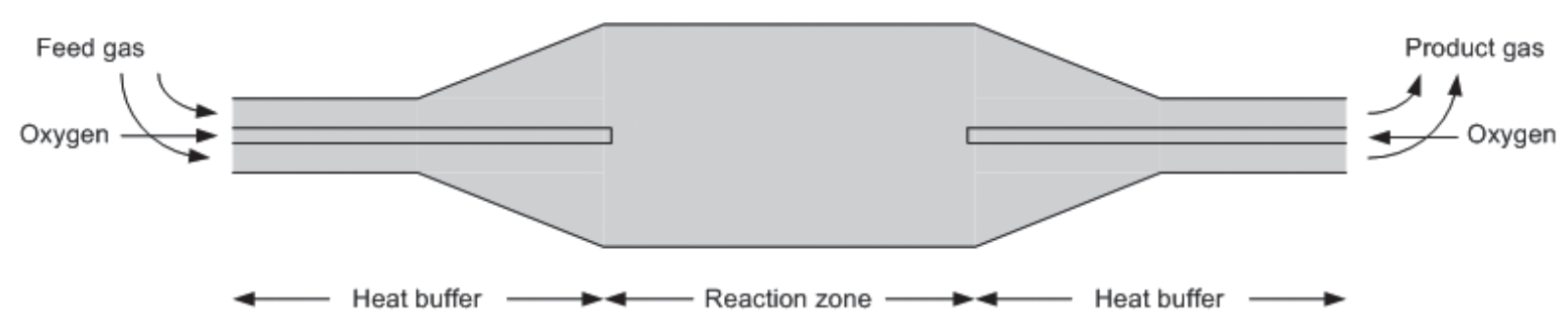

Fig. 1. Reactor design with a fully packed bed, showing the two independent oxygen inlets.

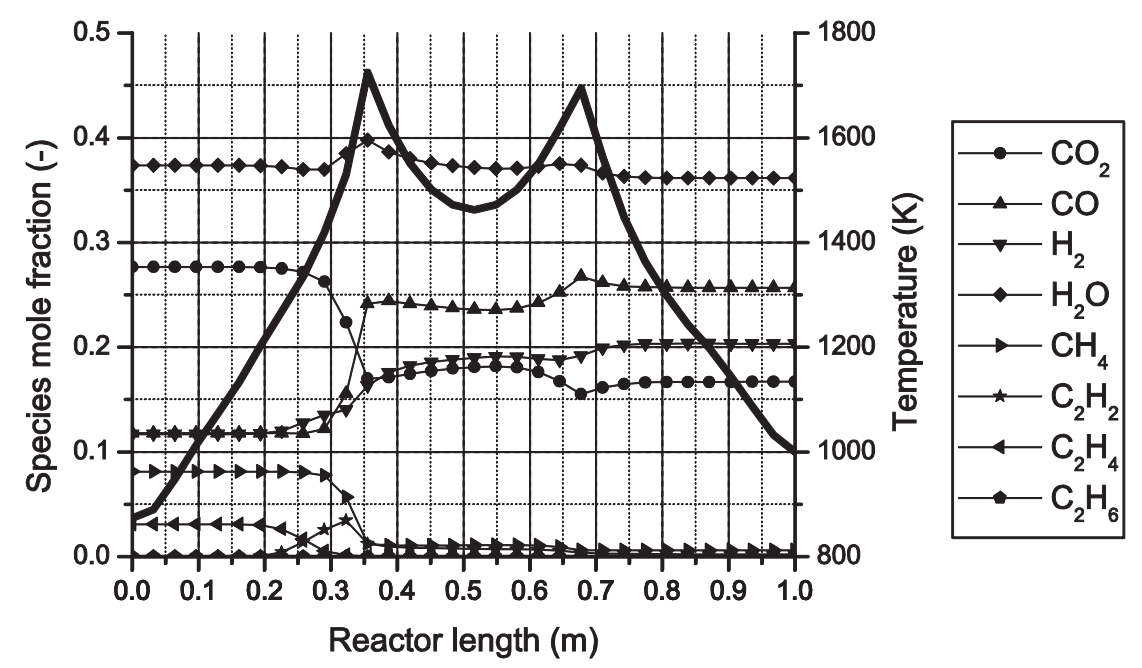

Fig. 2. Typical reactor profiles for the various components of the gasifier product gas. The heavy line shows the gas temperature profile along the reactor.

Oxygen is initially admitted at the end nearest the inlet. When the direction of flow is changed, oxygen is instead admitted at the end nearest the outlet, which becomes the current inlet. The final design of the reformer is summarized in Table 2, which also gives the inlet gas flow and temperature and the switching temperature used for all simulations.

In order to investigate the performance of the system when reforming a gasifier product gas under different conditions, simulations were conducted for different amounts of oxygen and at different pressures. Because the amount of steam in the gasifier product gas is determined by the gasifier, the steamto-carbon ratio in the gasifier product gas was not varied. In the natural gas simulations, the amount of oxygen added was varied, as well as the steam-to-carbon ratio, as steam has to be added to natural gas in order to reform it. The results of the simulations for the gasifier product gas are presented in Figs 2-4, while the results for the natural gas simulations can be seen in Figs 5-6. The cycle times for the gasifier product gas simulations were in the range 5-6 minutes and for natural gas 7-8 minutes.

Figure 2 shows typical profiles for species mole fractions and gas temperature from a simulation of gasifier product gas reforming. (The temperature of the solid bed is the same as the temperature of the gas.)

The reactor can be divided into three sections: the heat buffers at both ends and the central reaction zone, between the oxygen inlets. Following the inlet, from left to right in Fig. 2, the inlet gas cools the first heat buffer in the reactor before entering the reaction zone (first peak), where the temperature is increased. As the temperature increases through the reactor, in the first heat buffer, lower hydrocarbons 


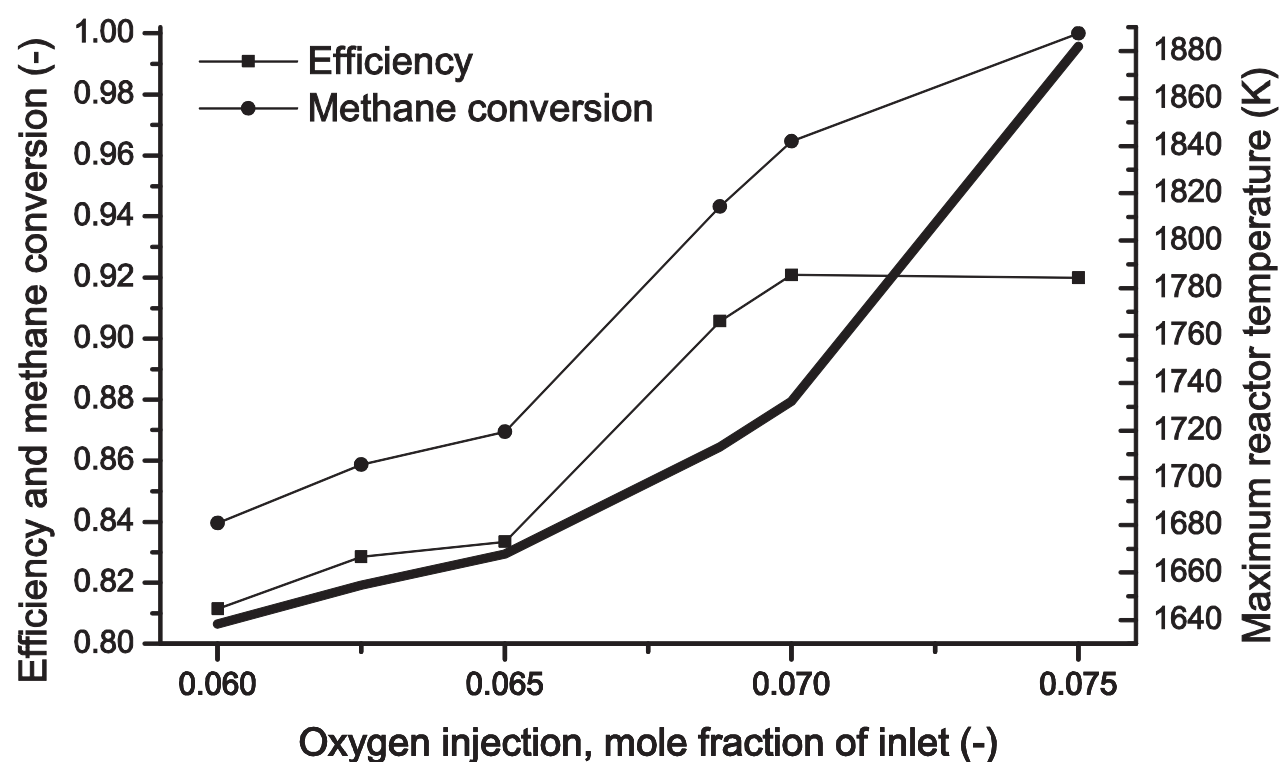

Fig. 3. Efficiency of the process and the methane conversion as a function of the amount of oxygen injected into the reactor when reforming gasifier product gas. The heavy line shows the maximum temperature as a function of the amount of oxygen added.

such as ethylene are reformed; this is also where the first soot formation would occur. The indication of soot formation can be seen in the figure as ethylene $\left(\mathrm{C}_{2} \mathrm{H}_{4}\right)$ is reacted to create acetylene $\left(\mathrm{C}_{2} \mathrm{H}_{2}\right)$ and $\mathrm{H}_{2}$. Methane, which is the most stable hydrocarbon, does not react until the temperature is above $1400 \mathrm{~K}$. In the reaction zone, after oxidation, the temperature decreases due to endothermic reactions. Methane is effectively reformed by steam and $\mathrm{CO}_{2}$, giving $\mathrm{H}_{2}$ and $\mathrm{CO}$. The second peak defines the beginning of the reaction zone when the direction of the flow is reversed. When the gas enters the second oxidation zone, the water-gas shift reaction changes the composition slightly, and most of the remaining hydrocarbons are reformed.

However, the reactor is never at steady-state. Even if the concentration profiles becomes rather stable, the temperature profile continues to develop until the change of flow direction. Therefore, the Fig. 2 shows just a snapshot of the reactors dynamic behaviour. Instead a pseudo-steady-state is defined. This occurs when the patterns, the temperature and concentration profiles, becomes identical for each repeated cycle. The recorded values in this section are taken during psuedo-steady-state operation. The maximum temperatures reported in Figs 3-6, are the maximum peek temperatures (see Fig. 2) obtained during pseudo-steady-state operation.

Figure 3 shows the change in reactor efficiency, methane conversion and maximum temperature $\left(\mathrm{T}_{\max }\right.$ ) for different oxygen inputs from 0.06 to 0.07 mole fraction of the total inlet mole flow.

It can clearly be seen that the methane conversion increases, as does the efficiency, as the amount of oxygen injected increases. However, there is a point at which increasing the amount of oxygen does not increase the efficiency, as more of the feed gas will be oxidised into carbon dioxide and water, increasing the temperature.

Varying the reactor pressure, while keeping the inlet flow constant, changes the residence time as can be seen in Fig. 4.

The short residence time at atmospheric pressure results in a low conversion of methane and higher temperature, as the endothermic reforming reactions are less evident. Increasing the pressure, i.e. in- 


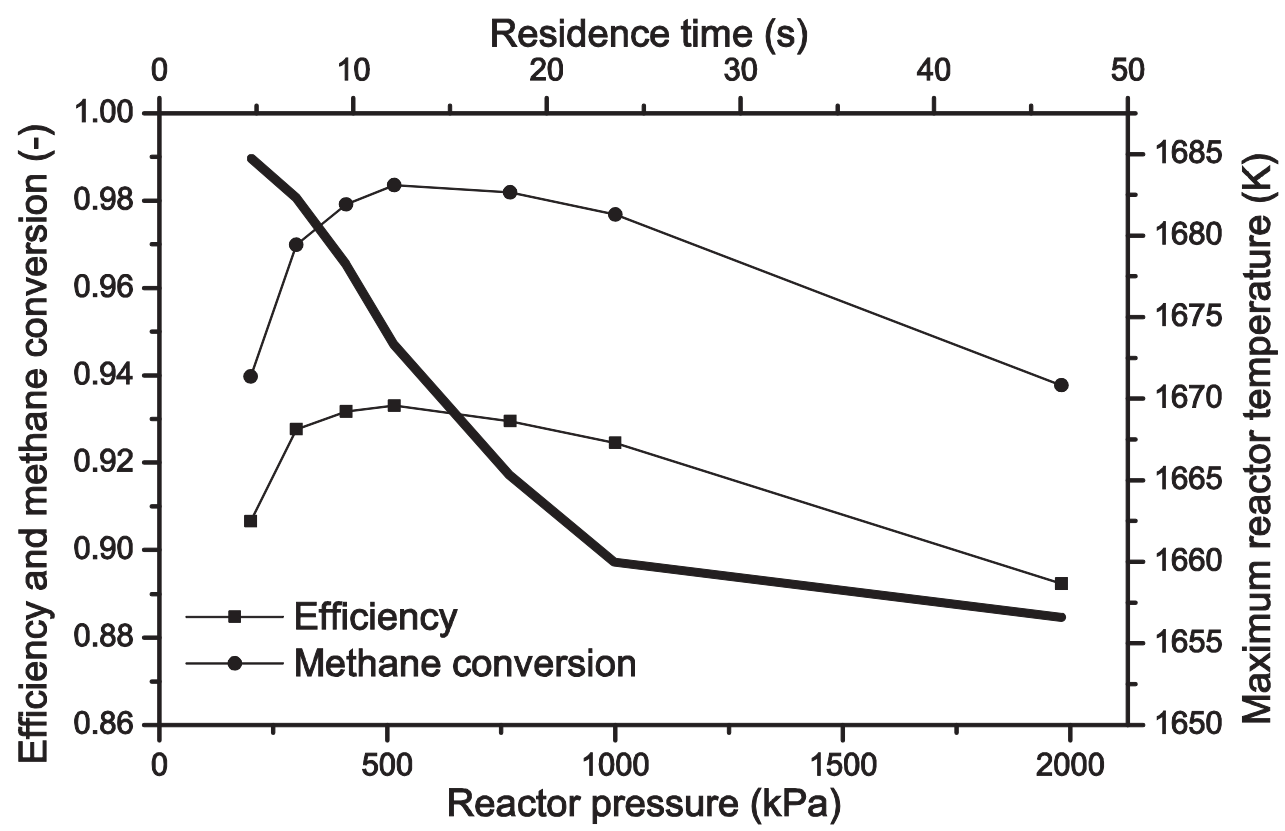

Fig. 4. Reactor efficiency and methane conversion as a function of absolute reactor pressure with a constant inlet flow when reforming gasifier product gas. The heavy line shows the maximum temperature as a function of reactor pressure.

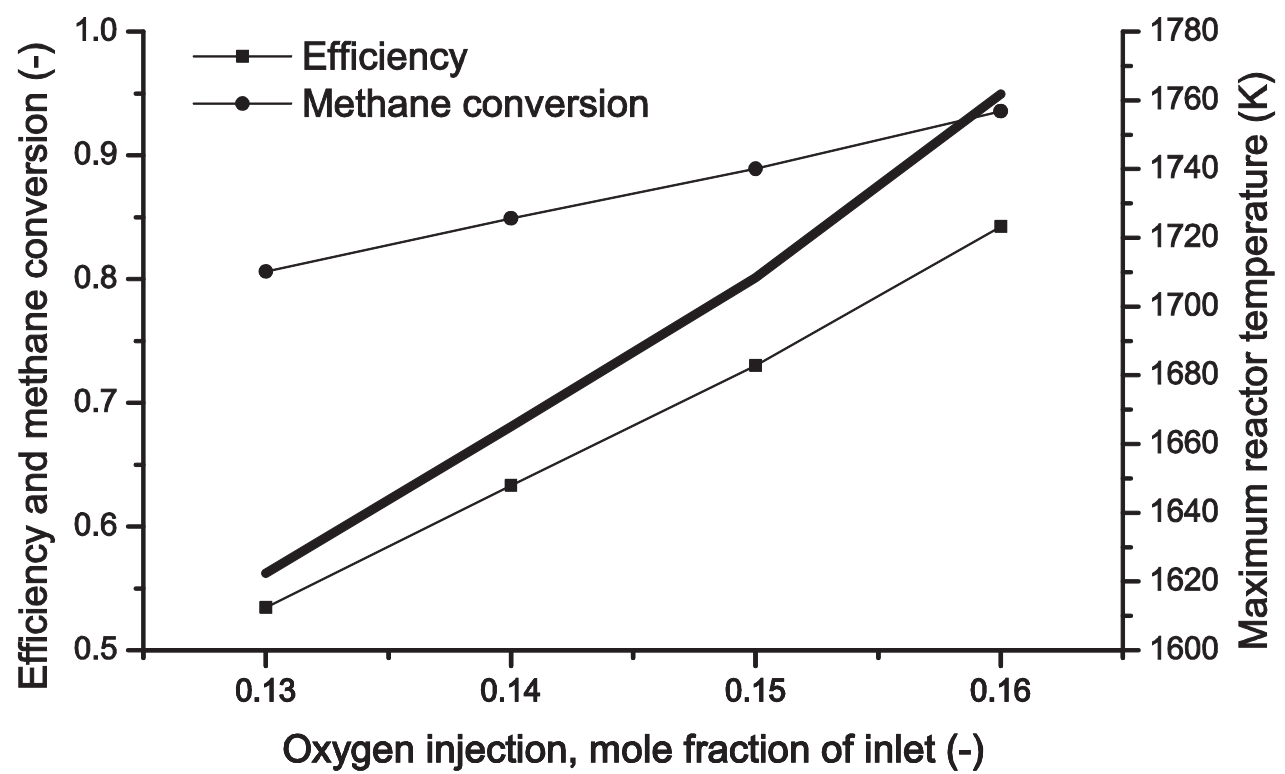

Fig. 5. Reactor efficiency and methane conversion as a function of the oxygen injected when reforming natural gas with a steam-to-carbon ratio of 1.4. The heavy line shows the maximum reactor temperature as a function of the proportion of oxygen added.

creasing the residence time, increases the reforming rate, which reduces the reactor temperature. A reduction in the reactor temperature decreases reforming, which results in lower methane conversion at higher residence times. 


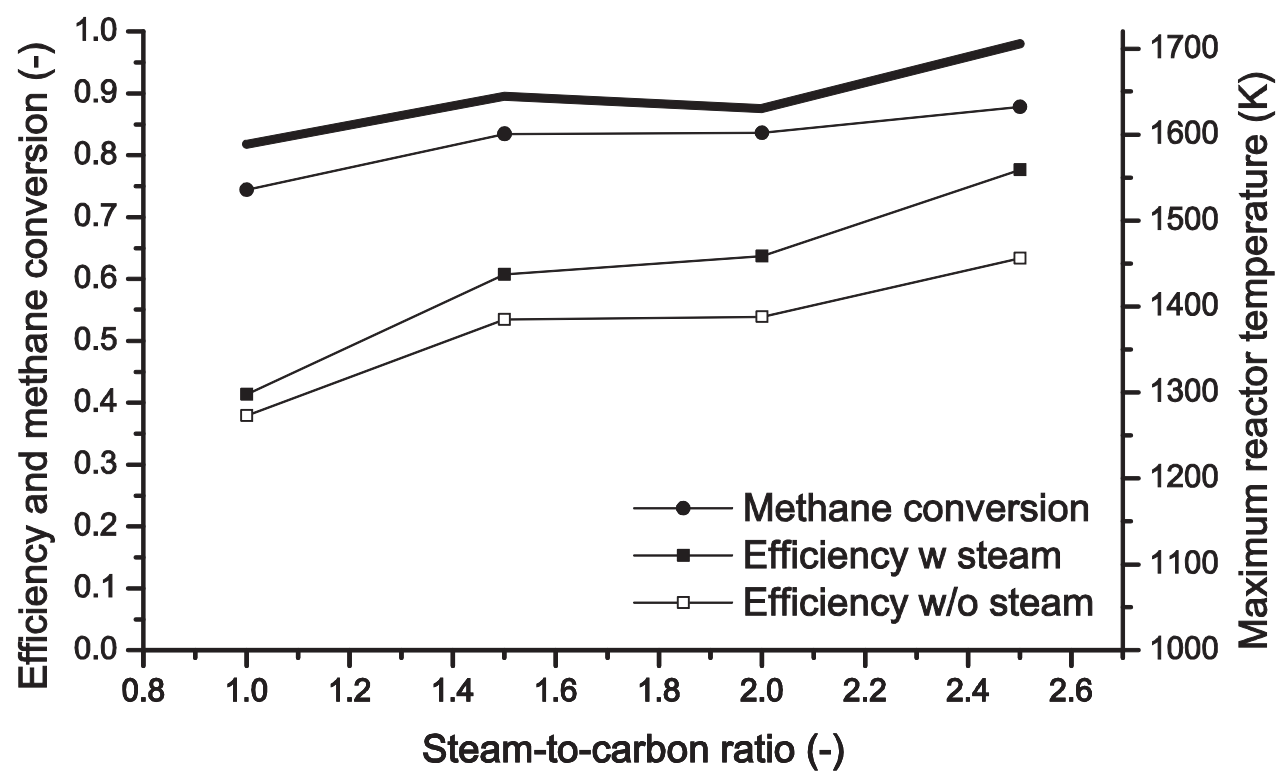

Fig. 6. Reactor efficiency and conversion of methane as a function of steam-to-carbon ratio for natural gas reforming. The heavy line shows the maximum reactor temperature as a function of steam-to-carbon ratio.

Figure 5 shows the reactor efficiency, the conversion of methane and the maximum temperature in the reactor for natural gas reforming, as a function of the oxygen added.

Natural gas, which contains more methane and thus requires more energy for reforming, also requires more oxygen than leaner gases such as gasifier producer gas. As in the case of gasifier product gas (Fig. 3), increasing the amount of oxygen added to the process increases the temperature and the methane conversion, resulting in higher reactor efficiencies. However, at the highest value of oxygen added, 0.16 , the temperature in the oxygen inlet zone exceeds $1723 \mathrm{~K}$, which could lead to thermal runaway.

Figure 6 shows the reactor efficiency, the conversion of methane and the maximum temperature in the reactor as a function of the steam-to-carbon ratio for the natural gas simulations.

The simulations were run at a constant oxygen-to-carbon ratio. It can be seen that the result of increasing the steam-to-carbon ratio is an increase in the reactor temperature, due to the decrease in energy input, which has a positive effect on the conversion. Increasing the steam-to-carbon ratio is also better for the equilibrium, which explains why the methane conversion as a function of steam-to-carbon ratio is not as linear as the conversion is for varying oxygen amount. Increasing the steam-to-carbon-ratio has a negative effect on the efficiency (with steam) as more steam is required, which can be seen in the figure as the gap between the efficiencies increase with increasing steam-to-carbon-ratios, but at the same time, it reduces soot formation. The efficiencies, with and without steam, can be considered to be two extremes. In an industrial application, the heat carried by the exit gas can be utilized, increasing the efficiency with steam somewhat.

\section{Conclusions}

This paper presents the results of simulations of a reverse-flow reformer for reforming a gasifier product gas for the production of synthesis gas. Results are also presented for natural gas reforming for comparison. 
Gasifier product gas contains a relatively low amount of methane and higher hydrocarbons, and a sufficient amount of steam for high methane conversion. When natural gas is used as feed, additional steam must be added to the inlet in order to achieve an acceptable conversion of methane. It is also necessary to increase the residence time as the concentration of methane increases. The reactor designed seems well suited for reforming the methane present in a gasifier product gas. Processing gases with high methane contents, such as natural gas, requires more heat than gases with low methane contents, and the regenerative reformer, with the chosen design, is therefore not as well suited for reforming natural gas.

The two most important parameters for the reforming of methane are the reactor temperature and residence time, both of which are dependent on a number of other parameters, such as the oxygen inlet flow, reactor dimensions, reactor pressure, etc. It was difficult to compare the cases of gasifier producer gas and natural gas as the temperature in the reactors differed. Natural gas reforming requires more energy, in absolute terms, as it contains more methane, which lowers the temperature in the reaction zone more than in the case of gasifier producer gas. The temperature falls faster, in the case of natural gas, as more methane is present, requiring either longer residence times or more oxygen to be added, resulting in higher reactor temperatures. However, it is not practical to increase the temperature beyond $1700-1800 \mathrm{~K}$ as this is close to, or above, the melting point of most materials that could be used as bed material and reactor lining. A higher reactor temperature also consumes more of the chemically bonded energy in the outgoing gas and thus lowers the efficiency.

The assumed composition of the gasifier producer gas was typical for that of a pressurised circulating fluidised bed, but the reactor should be suitable for reforming any gas containing 0-10 vol- $\%$ methane.

\section{Notation}

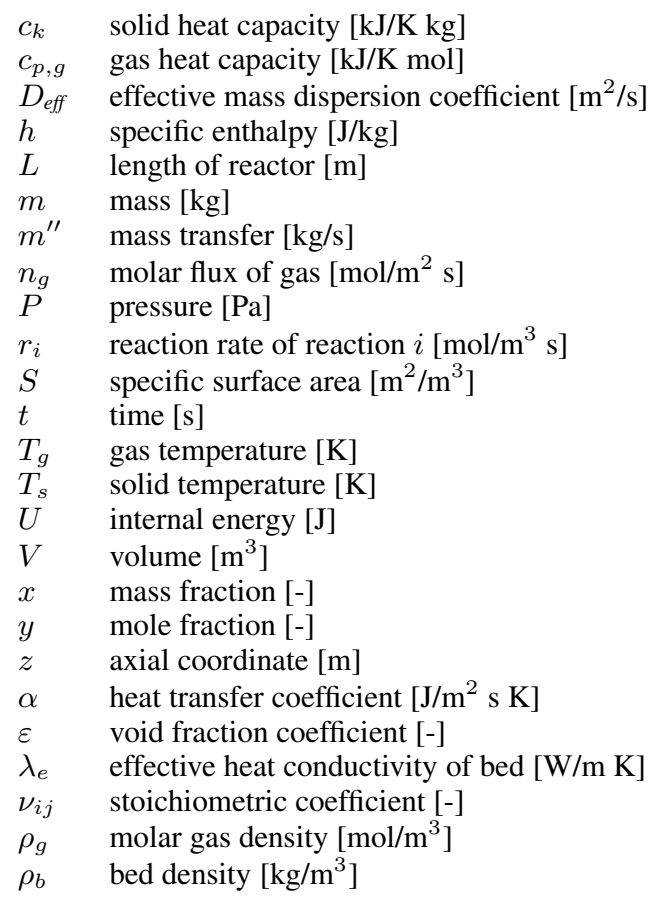




\section{Acknowledgments}

The authors are grateful for the financial support provided by the European Commission within the framework of the FP7 Integrated Project "GreenSyngas" (Project No. 213628). We would also like to thank the Swedish Energy Agency, STEM, and E.on for their financial support.

\section{References}

[1] S. Albertazzi, F. Basile, J. Brandin, J. Einvall, G. Fornasari, C. Hulteberg et al., Effect of fly ash and H2S on a Ni-based catalyst for the upgrading of a biomass-generated gas, Biomass and Bioenergy 32 (2008), 345-353.

[2] J. Sehested, Four challenges for nickel steam-reforming catalysts, Catal Today 111 (2006), 103-110.

[3] C. Hulteberg, Sulphur-tolerant catalysts in small-scale hydrogen production, a review, Int J Hydrogen Energy 37 39783992.

[4] Y.S. Matros and G.A. Bunimovich, Control of Volatile Organic Compounds by the Catalytic Reverse Process, Industrial \& Engineering Chemistry Research 34 (1995), 1630-1640.

[5] G.K. Boreskov and Y.S. Matros, Flow reversal of reaction mixture in a fixed catalyst bed - a way to increase the efficiency of chemical processes, Applied Catalysis 5 (1983), 337-343.

[6] Y.S. Matros, G.A. Bunimovich, S.E. Patterson and S.F. Meyer, Is it economically feasible to use heterogeneous catalysts for VOC control in regenerative oxidizers? Catal Today 27 (1996), 307-313.

[7] Y.S. Matros and G.A. Bunimovich, Reverse-flow operation in fixed bed catalytic reactors, Catalysis Reviews - Science and Engineering 38 (1996), 1-68.

[8] G.K. Boreskov and Y.S. Matros, Unsteady-state performance of heterogeneous catalytic reactions, Catalysis Reviews Science and Engineering 25 (1983), 551-590.

[9] D. Neumann and G. Veser, Catalytic partial oxidation of methane in a high-temperature reverse-flow reactor, $A I C h E$ Journal 51 (2005), 210-223.

[10] A. Mitri, D. Neumann, T. Liu and G. Veser, Reverse-flow reactor operation and catalyst deactivation during hightemperature catalytic partial oxidation, Chemical Engineering Science 59 (2004), 5527-5534.

[11] D. Neumann, V. Gepert and G. Veser, Some Considerations on the Design and Operation of High-Temperature Catalytic Reverse-Flow Reactors, Industrial \& Engineering Chemistry Research 43 (2004), 4657-4667.

[12] D. Neumann, M. Kirchhoff and G. Veser, Towards an efficient process for small-scale, decentralized conversion of methane to synthesis gas: combined reactor engineering and catalyst synthesis, Catal Today 98 (2004), 565-574.

[13] R.F. Blanks, T.S. Wittrig and D.A. Peterson, Bidirectional adiabatic synthesis gas generator, Chemical Engineering Science 45 (1990), 2407-2413.

[14] N.S. Kaisare, J.H. Lee and A.G. Fedorov, Hydrogen generation in a reverse-flow microreactor: 2. Simulation and analysis, AIChE Journal 51 (2005), 2265-2272.

[15] N.S. Kaisare, J.H. Lee and A.G. Fedorov, Operability Analysis and Design of a Reverse-Flow Microreactor for Hydrogen Generation via Methane Partial Oxidation, Industrial \& Engineering Chemistry Research 44 (2005), 8323-8333.

[16] T. Kikas, I. Bardenshteyn, C. Williamson, C. Ejimofor, P. Puri and A.G. Fedorov, Hydrogen Production in a ReverseFlow Autothermal Catalytic Microreactor: From Evidence of Performance Enhancement to Innovative Reactor Design, Industrial \& Engineering Chemistry Research 42 (2003), 6273-6279.

[17] U. Friedle and G. Veser, A counter-current heat-exchange reactor for high temperature partial oxidation reactions I. Experiments, Chemical Engineering Science 54 (1999), 1325-1332.

[18] M.K. Drayton, A.V. Saveliev, L.A. Kennedy, A.A. Fridman and Y.-E. Li, Syngas production using superadiabatic combustion of ultrarich methane-air mixtures, Symp (Int) Combust, [Proc] (27th 1998), 1361-1367.

[19] M. Toledo, V. Bubnovich, A. Saveliev and L. Kennedy, Hydrogen production in ultrarich combustion of hydrocarbon fuels in porous media, International Journal of Hydrogen Energy 34 (2009), 1818-1827.

[20] K.V. Dobrego, N.N. Gnezdilov, S.H. Lee and H.K. Choi, Methane partial oxidation reverse flow reactor scale up and optimization, International Journal of Hydrogen Energy 33 (2008), 5501-5509.

[21] K.V. Dobrego, N.N. Gnezdilov, S.H. Lee and H.K. Choi, Partial oxidation of methane in a reverse flow porous media reactor. Water admixing optimization, International Journal of Hydrogen Energy 33 (2008), 5535-5544.

[22] M.-Z. Xie, J.-R. Shi, Y.-B. Deng, H. Liu, L. Zhou and Y.-N. Xu, Experimental and numerical investigation on performance of a porous medium burner with reciprocating flow, Fuel $\mathbf{8 8}$ (2008), 206-213.

[23] G.P. Smith, D.M. Golden, M. Frenklach et al., GRI-Mech 3.0, 2000, available at: http://www.me.berkeley.edu/gri_mech/ $(7 / 03 / 2015)$.

[24] A. Dufour, S. Valin, P. Castelli, S. Thiery, G. Boissonnet, A. Zoulalian et al., Mechanisms and Kinetics of Methane Thermal Conversion in a Syngas, Industrial \& Engineering Chemistry Research 48 (2009), 6564-6572. 
[25] Lu K, Song C, Subramani V. Hydrogen and Syngas Production and Purification Technologies. New Jersey: John Wiley \& Sons, Inc.; 2010.

[26] CHRISGAS. Clean Hydrogen-rich Synthesis Gas - fuels from biomass. Intermediate Report. Växjö: Swedish Energy Agency; 2008.

[27] Design of new DDASPK for sensitivity analysis Technical Report, Santa Barbara: Department of Mechanical and Environmental Engineering, University of California; 1999. 